\title{
READING SPEED LEVEL AND COMPREHENSION IN SECOND LANGUAGE READING
}

\author{
M. Sayid Wijaya \\ Universitas Islam Negeri (UIN) Raden Intan, Lampung \\ Email: sayidwijaya@radenintan.ac.id
}

\begin{abstract}
Fluent readers are characterized by their ability in comprehending reading text flawlessly. They need no such a significant delay to process either word recognition or world knowledge while putting some efforts to get the gist of the text. Thus, their reading speed would increase by the time their word recognition skill improved. This also implicates their reading comprehension as well since they are skillful enough to relate what they know about the text with the text itself. However, that condition happened differently to students who joined Reading for General Purposes class. Some students who read in normal speed varied in their reading comprehension score. Students' reading speed level must have yielded the approximate score to their speed level, moderate score. This occurrence leaded the writer to investigate if there is any correlation between students' reading speed level and their reading comprehension. Thus, correlational research design was deployed in this research. Sample of this research were students who joined writer's Reading for General Purposes class, 74 students. The data were collected by using tests, reading speed test and reading comprehension. After collecting the data, the writer analyzed them by using Spearman's Rank Order Correlation to test the hypothesis. Since the result of Spearman's rho value Sig. $=.608$ $>\alpha=.05$, alternative hypothesis was not accepted which meant that there was no correlation between students' reading speed level and their reading comprehension.
\end{abstract}

Keywords: Reading speed level, reading comprehension, second language reading

\section{INTRODUCTION}

Reading is an activity that has a purpose (Klinger, Vaughn, \& Boardman, 2007). Before, diving into the act of reading, a reader subconsciously need to realize what he or she is trying to earn from the reading text. That curiosity brings the mind to focus mainly on the information to obtain. The eyes, then, scan each line to hunt the keyword, which will lead to that information. Therefore, setting the purpose before coming to the act of reading is beneficially crucial.

Reading is a complex process involving a network of cognitive actions that work together to construct meaning
(Baker and Brown 2002; Block and Pressley 2002; Pearson 2002; First Group and Samuels 2002; Ruddell, Ruddell, and Singer 1994 in Dorn and Soffos, 2005). Craik and Lockhart (1972 in Chen, Dronjic, \& Park, 2016) proposed a continuum of reading processes from shallow to deep. According to this model, memory and learning are dependent on the depth of processing. When readers comprehend text, they progress from shallow to deep levels of processing. Shallow processing, such as visual word processing, is carried out on the surface of text, while deep, semantic processing involves enriched thought about the meaning of words and their associations. Deep processing leads to higher levels of 
retention and learning from text (Kirby, Cain, \& White, 2012 in Chen, Dronjic, \& Park, 2016).

In reading, the main point of reading is to grasp the message or ideas the writers want to convey to the readers (Wijaya, 2016). It means that the main purposes of reading is to obtain information that contains in the reading text. If students are unable to grasp that information, they miss the main point of reading itself that will lead them into poor readers. Furthermore, unlike good readers, poor readers lack the decoding, word reading, and fluency skills to free up cognitive functioning so that their full attention can be focused on learning from reading (Klinger, Vaughn, \& Boardman, 2007).

Different from poor readers, good readers may extract the holistic pattern of words, whereas poor readers rely on the individual features that compose words (Meyler \& Breznitz, submitted) a manner of decoding that takes longer (Biemiller, 1978 in Bernitz 2008). This shows that good readers understand the text by not analyzing word-by-word meaning, but the overall word construction that builds up the meaning. This will speed up students' reading speed and improve their comprehension as well.

From those discussions, it can be summed up that when students are able to process those components subconsciously, they are able to read faster and are able to comprehend the textbetter. So, the faster they read, the better they comprehend the text. This shows that students' reading speed level determines their comprehension. In contrast to that conclusion, when the writer tried to explore students' reading comprehension in a due time to the students who was joining Reading for General Purposes class, he found that students' reading comprehension score differed significantly among them. Therefore, the writer would like to investigate if there is any correlation between students' reading speed level and their reading comprehension.

\section{LITERATURE REVIEW}

\section{Fluent Readers}

Reading researchers agree that fluent reading is based primarily on the equality and rate of identification and recognition of the symbols and sounds of single and multilateral unit (Breznits, 2008).

Fluent readers find no difficulties in comprehending what they read. Fluent reading is when a reader's recognition of words in context is so transparent that readers are able to move from the text to comprehension without conscious attention to words (Paris \& Stahl, 2005). For the fluent readers, focusing on recognizing words is not the main concern for them. They flawlessly understand the idea in the text without paying more attention to unknown words. More fluent readers would be expected to read text with few miscues, few meaning-changing miscues, and with high rates of self-corrected miscues (Paris $\&$ Stahl, 2005).

Westwood (2001) mentioned that fluent readers use the code automatically so that the reading process is smooth and relatively effortless. They also build up a repertoire of words they can recognize instantly by sight. Different from fluent reader, in non-fluent readers, a single process alone might require the full extent of cognitive resources. In such cases, when word recognition uses up all of the reader's cognitive resources, other component processes of reading, such as comprehension, cannot be processed simultaneously (Breznits, 2008). Thus, fluent readers' reading speed in comprehending a text is better than non-fluent readers.

Many activities are designed to promote fluent reading. Dorn and Soffos (2005) propose this designed to promote fluent reading and comprehending 
strategies. The first is independent reading. In independent reading, as the name suggest, a reading reads a text alone. At the emergent and early levels, students might keep their own basket, or tub, of familiar books for use in independent reading; or they can select a book from the classroom library. The second is paired reading. In paired reading, two students at different reading levels sit side by side and read a text together. The teacher generally, determines the pairs, having the more skilled reader support the lower-level reader at points of difficulty, and keeping the focus on fluency and comprehension. The third is buddy reading. In buddy reading, two students at similar reading level read together. They can alternate pages, read in unison, or echo each other. Unlike paired reading, where the teacher pairs the students, in buddy reading students select their own pairs. Buddy reading can be an extension of a guided reading or literature discussion group. The fourth is recorded reading. In recorded reading, a student listens to a prerecorded text at instructional level and reads aloud with the recording. (Dorn \& Soffos, 2005)

Thus, such activities can foster poor readers to be good readers. However, teacher's assistance in supervising students' progress also is needed. Thus, selecting the appropriate reading activities will help student develop their reading ability well.

\section{Reading Speed}

Concerning reading speed, among the strongest and earliest findings of these investigations, was that silent reading was superior to oral reading in both speed and comprehension (Sadoski, 2004). Therefore, asking students to read a text silently is better for their reading speed and comprehension rather than asking them to read a text aloud. It is possible that by reading silently students' motoric focus is mainly on eyes movement to grasp the gist of the text, not focusing the other movement like tongue and mouth movement. Further, within the overall account of reading ability, the notion of fluency was presented in terms of "effective reading speed," which was itself seen as an outcome of comprehension, decoding accuracy, and rate of reading, measured by words per minute (Breznits, 2008). In this case, rate of reading or reading speed level was one of indicators showing the fluency on students in reading the text beside comprehension and decoding accuracy.

To measure students' reading speed level, this reading speed level category can be used as stated in Table 1. This category can be used if the text consists of 500 words (Fry 2011).

Table 1. Reading Speed Level

\begin{tabular}{cc}
\hline Second & Level \\
\hline 45 seconds or less & Very fast \\
$46-60$ seconds & Fast \\
$61-90$ seconds & High average \\
$91-119$ seconds & Average \\
$120-150$ seconds & Slow \\
151 seconds or more & Very slow \\
\hline
\end{tabular}

\section{Increasing reading speed}

It is a great idea to increase reading speed to help us work on the reading text in no time. To find genera idea of the text, these tips are very useful in accordance with skimming technique. Here are the tips proposed by Fry (2011) to increase reading speed. The first is to focus the attention and concentration. The second is to eliminate outside distractions. The third is to provide for an uncluttered, comfortable environment. The fourth is to not get hung up on single words or sentences, but look up (in the dictionary) key words that we must understand in order grasp an entire concept. The fifth is to try to grasp overall concepts rather than attempting to understand every detail. The sixth is if we find ourself moving our lips when we read (vocalization), practice reading with a pen or some other 
(nontoxic, nonsugary) object in our mouth. If it falls ours while we are reading, we know we have to keep working. The seventh is to work on building our vocabulary. we may be reading slowly (and/or having trouble understanding what we read) because our vocabulary is insufficient for our reading level. The eighth is to read more and more often. Reading is a habit that improves with practice. The ninth is to avoid rereading words or phrases. According to one recent study, an average student reading at 250 words per minute rereads 20 time per page. The slowest readers reread the most.

Those nine tips are beneficially crucial to increase reading speed, especially in certain condition like in preparing for examination. There is specific time allotment given to accomplish all the reading questions of many passages. Making mistakes in managing time during examination will lead us to having bad score and will make students become poor readers.

\section{Reading Process}

There are three prominent theories on reading process namely bottomup processing, top-down processing, and interactive processing. Those reading processes surely affect either students' reading speed or their reading comprehension.

\section{Bottom-up processing}

In bottom-up processing, readers must first recognize a multiplicity of linguistic signals (letters, morphemes, syllables, words, phrases, grammatical cues, discourse markers) and use their linguistic data processing mechanisms to impose some sort of order on these signals (Brown, 2000). In other words, bottom-up processing starts to work from small units of linguistic elements like orthographic processing. Therefore, readers initially need to be able to master fundamental bottom-up strategies for processing separate letters, words, and phrases (Brown, 2004).

Breznitiz (2008) pointed out that lower order, or bottom-up, processing is data driven. Reading processes that rely heavily on lower order processing include letter identification and word recognition. This is in line with Brown (2000 and 2004) who mentioned that the main point of bottom-up processing is word recognition, referring to linguistic view. In this processing, readers start their comprehension from recognizing smaller units of linguistic components like orthographies or letters.

\section{Top-down processing}

Higher order, or top-down, processing is concept driven. When one begins to read, reading comprehension dependent on the success of lower order processing word identification, but as competence is gained, reading comprehension comes to be explained more by higher language competence than by word identification skills (Perfetti, 1985 in Breznitz, 2008). In this vase, when readers have been familiar with bottom-up processing, they will step up to top-down processing. Therefore, topdown processing works only after bottomup processing is successfully achieved by the readers.

In line with Prefetti (1985), Brown (2000) stated that virtually all reading involves a risk- a guessing game, in Goodman's word - because readers must, through puzzle-solving process, infer meanings, decide what to retain and not to retain, and move on. This is where a complementary method of processing written text is imperative: top-down, or conceptually driven, processing in which we draw on our intelligence and experience to understand a text. in this case, to reveal what is hidden within the text, the readers need to employ their intelligence and prior knowledge so the main purpose of reading, getting the gist of the text, is accurately 
attained. Thus, top-down processing relies on students' insight or knowledge to comprehend the text.

\section{Interactive processing}

In the interactive view of reading comprehension, bottom-up processing and top-down processing complement one another and function interactively as a process between reader and the text (Chen, Dronjic \& Helms-Park, 2016). When people are reading, they need both the information flowing upward from the bottom to the top and the information flowing downward from the top to the bottom in order to understand the meaning successfully (Birch, 2015). Thus, both process are required to make comprehension occurs.

Birch (2015) illustrated how bottom-up and top-down processing word together in comprehension were as perception and recognition of letters lead to recognition of words, from which people construct meaning. In the other direction, contextual information, inferences, and world knowledge influence the processing strategies at lower level. World knowledge can affect people's expectation about words and meaning which can allow them recognize some words faster than others or understand some meaning faster than others. Thus, a reader continually shifts from one focus to another, now adopting a top-down approach to predict probable meaning, then moving to the bottom-up approach to check whether that I really what the writer says (Nuttell 1996 in Brown, 2000).

\section{Reading Comprehension}

Being able to comprehend the text is the main goal of every reader. Therefore, to read the text well, students are demanded to have proficient skills in reading such as determining main idea, finding stated and unstated details, or recognizing unknown words. Those skills are required to be able to dig information within the text. Thus, it needs to clarify what reading comprehension is.

Reading comprehension, ultimately, is the process of constructing meaning by coordinating a number of complex processes that include word reading, word and world knowledge, and fluency (Anderson, Hiebert, Scott, \& Wilkinson, 1985; Jenkins, Larson, \& Fleischer, 1983; O'Shea, Sindelar, \& O'Shea, 1987 in Klinger, Vaughn, \& Boardman, 2007). Kendeou et al. (2007 in Grabe, 2009) pointed out that comprehension is not a unitary phenomenon but rather a family of skills and activities. A general component in many definitions of comprehension is the interpretation of the information in the text ... At the core of comprehension is our ability to mentally interconnect different events in the text and form a coherent representation of what the text is about. In this case, the processing occurred when readers comprehend a text involves mental activities that relate what happenings are in the text and the general information of the text. Comprehension is easy when the domain knowledge is high. In this case, comprehension will be achieved better when the readers have more knowledge of the materials (Wijaya, 2014).

Many linguists think that reading comprehension is based on both the microstructure and the macrostructure of the text. The microstructure consists of all the propositions in a text, that is, the semantic information written in the sentences. On the other hand, all the sentences and the information in them create a macrostructure for the text, for example, in what order and how the things are presented in the text. Together the micro- and macrostructure form a text base, which is the meaning of the text as it is actually expressed by the text (Kitsch \& Rawson, 2005 in Alderson, Haapakangas, Huhta, Nieminen, \& Ullakanoja, 2015). To be precise, defining reading comprehension is quite complex since it covers low and high-interrelated aspects of linguistic and 
nonlinguistic components.

Concerning reading comprehension assessment, Brown (2004) mentioned that a set of questions in reading comprehension should cover the comprehension of these seven features. They are main idea, expressions/idioms/phrases in context, inference, grammatical features, detail, excluding facts not written, supporting idea(s), and vocabulary in context. Those features can be used to assess students' reading comprehension.

\section{RESEARCH METHOD}

This was correlational research design that was conducted to investigate the correlation between reading speed level and reading comprehension. All students who enrolled Reading for General Purposes class taught by the writer was the sample of this research. There were 18 students from class D, 29 students from class E, and 27 students from class F. Therefore, the total sample of this research was 74 students.

In collecting the data, the writer deployed a reading text and reading comprehension questions adapted from Fry's reading speed and reading comprehension tests. Students were asked to read a text entitled "The Original Incarnation of CocaCola" in pair and answered four reading comprehension questions. In pair, one student was reading the text, consisting of five paragraphs, when another student recorded his/her reading speed by using timer in his/her hand phone. After the student read the text, then the text was taken away. After that, she or he was given four reading comprehension questions asking about the content of the text she or he had just read to be answered without looking back to the text. After answering the questions, another student did the same as the first student did in that pair.

Students' reading speed was recorded in second. The writer also described students' reading speed level based of Fry's reading speed level. Students' reading comprehension score was scored based on dichotomous score. 1 was given to the correct answer and 0 was given to the incorrect answer. The total correct answer, then, was divided by the total number of the item and times 100 . The scoring formula is as follow:

$$
\text { Final score }=\frac{\text { Correct answer }}{\text { Total number of item }} \times 100
$$

After gaining students' reading speed level and students' reading comprehension score, the writer did not check the normality of the data since the statistic formula the writer used was Spearman's Rho Correlation, non-parametric statistics, so it did not need to fulfill statistical assumptions for parametric statistics. Spearman's Rho Correlation was used because one of the data, students' reading speed level, were in ordinal scale.

The hypotheses in this research were:

Ho: There is correlation between students' reading speed and their reading comprehension.

Ha: There is no correlation between students" reading speed and their reading comprehension.

\section{FINDINGS AND DISCUSSION}

\section{Findings}

There were two data obtained in this research. The first data were students' reading speed level and the second data were students' reading comprehension. Those data were obtained by using two different instruments. The first instrument was reading text to see students' reading speed level and the second instrument was reading comprehension test to see students' comprehension after reading the text on their respectively speed level.

\section{Students' reading speed level}


As previously discussed that students' reading speed level was aimed at knowing how fast students can read a text to attain the information within the text itself. The text was about The Original Incarnation of Coca-Cola, consisting of five paragraphs. This test was administered to 74 students. The result of students' reading speed level was presented in Table 2.

Table 2. The Result of Students' Reading Speed Level

\begin{tabular}{|c|c|c|c|}
\hline Second & Level & $\begin{array}{c}\text { Number of } \\
\text { Student }\end{array}$ & $\%$ \\
\hline $120-150$ & slow & 8 & 11 \\
\hline $\begin{array}{c}151 \text { or } \\
\text { more }\end{array}$ & $\begin{array}{l}\text { very } \\
\text { slow }\end{array}$ & 66 & 89 \\
\hline \multicolumn{2}{|c|}{ Total } & 74 & \\
\hline
\end{tabular}

From Table 2., it could be seen that there were only two levels of students' reading speed level found in this research. They were slow level and very slow level. Only 8 students were in slow level speed ranging from 120 to 150 second in reading the text. 66 students were in very slow level speed ranging from 151 to 398 second.

\section{Students' reading comprehension}

There were four items in reading comprehension test which was adapted from Fry. Each item examined different aspects in reading comprehension. One item asked about unstated detail and the others asked about stated details. This test was given after each student read the text. Table 2 . demonstrated the result of students' reading comprehension score.

Table 3. The Result of Students' Reading Comprehension Test

\begin{tabular}{ccc}
\hline Score & $\begin{array}{c}\text { Number of } \\
\text { Student }\end{array}$ & $\mathbf{\%}$ \\
\hline 0 & 16 & 22 \\
25 & 33 & 45 \\
50 & 18 & 24 \\
75 & 7 & 9 \\
Total & $\mathbf{7 4}$ & $\mathbf{1 0 0}$ \\
\hline
\end{tabular}

From Table 3., it could be seen that the minimum score was zero and the maximum score was seventy-five which meant that there were some students who got no correct answers and some students who got three correct answers. Further, there were sixteen who got zero, thirty-three students who got twenty-five, eighteen students who got fifty, and seven students who got seventy-five. Unfortunately, not a single student was able to answer all items correctly.

\section{Hypothesis testing}

Since reading speed level data were in ordinal scale, the writer did not need to fulfill normality assumption to use non parametric statistics, Spearman's Rank Order Correlation. To calculate Spearman's rho correlation, SPSS v16 was deployed. Table 3 presented the result of computation.

\section{Table 4. The Result of Spearman's Rho Computation}

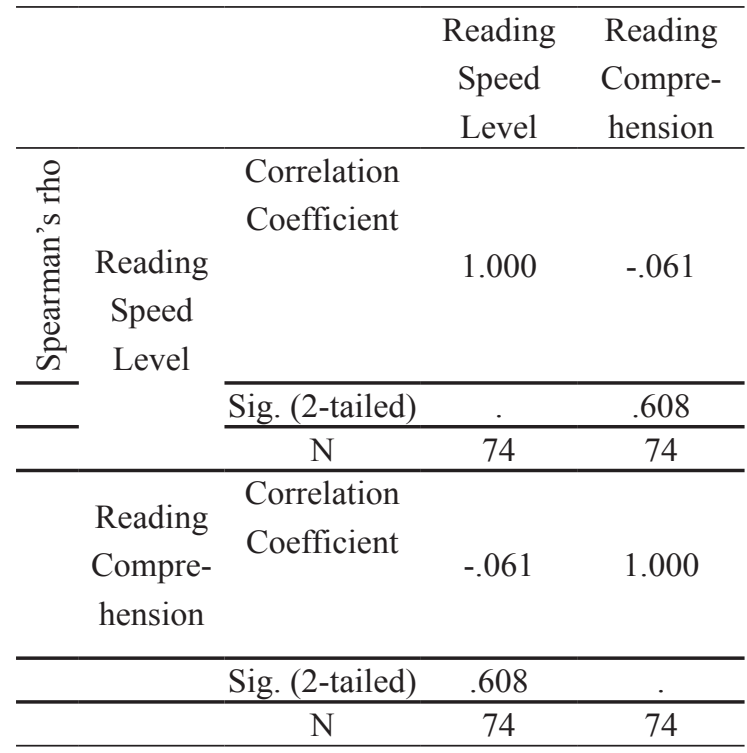

Spearman'srhocorrelation coefficient was -.061 and Sig. (2-tailed) was .608. The correlation was in negative direction and it was in modest correlational strength. To test the hypothesis, then, the writer compared $\mathrm{p}$ value $(\alpha=.05)$ to $\mathrm{Sig}$. value. Since $\alpha=.05<$ Sig. .608, it could be inferred that alternative hypothesis was not accepted which meant there was no significant correlation between 
students' reading speed level and their reading comprehension.

\section{DISCUSSION}

Reading speed and reading comprehension are two different aspects in reading which are related to students reading development. To be a fluent reader they need to read as fast as possible to save the time while getting the gist of the text. There is no need to think about unknown words in the text but guessing their meaning using context clues or their grammatical function. Thus, it was assumed that reading comprehension speed level was correlated to reading comprehension.

Concerning that assumption, this research was conducted to investigate the correlation between students' reading speed level and their reading comprehension. Students' reading level was measured by asking a student to read the text that consisted of five paragraphs and asking another student to record the time needed to complete reading the text. Further, to measure students' reading comprehension of the text being read, they were asked to answer four questions related to the text right after they finished reading the text.

The result of students' reading speed level illustrated that most of them still needed more time to read five paragraphs. Only 8 (11\%) students who were categorized as slow readers, and the rest, 66 $(89 \%)$ students, were categorized as very slow readers. None of them were in very fast, fast, high average, and average speed level. In this case, it could be seen that they were not fluent readers yet. There were so many possibilities emerged. Since the test was conducted in the first meeting of the first reading course, Reading for General Purposes, their experience and their abilities in either lower level processing or higher level processing were not tempered yet. Lower level processing was related to word knowledge like orthographic processing and word recognition while higher level processing was related to comprehension like bringing prior knowledge to the act of reading. Therefore, students' ability in processing lower level and higher level were the possible factors that determined their reading speed level.

In conjunction with the result of students' reading speed level, the result of students' reading comprehension level illustrated that most students, 33 (45\%) students, answered one question correctly in those varieties of time. This meant that even with the longer time they had spent in reading the text, their chance to answer three correct answers was not more than nine percent (9\%). Fry (2011) clarified that a good reader should be reading fast or very fast and have gotten at least three of the four questions correct. This implicated that those students could not be pointed as good readers since their reading speed level was not in fast category and only seven students who answered three correct answers, missing fast category.

The result of students' reading speed level and their reading comprehension was also strengthened by the result of hypothesis test which revealed that there was no correlation between students' reading speed level and their reading comprehension, $\alpha$ $=.05<$ Sig. .608. This could be seen from the result of reading comprehension which showed that there were seven students who were able to answered three questions correctly although their reading speed level was in slow and very slow category. This also revealed that Spearman's Rho was -.061which demonstrated negative correlation between those variables. Negative correlation meant that the higher the students' reading speed level was, the less comprehension they suffered. Further, being in slow category also did not guarantee that they were able to answer at least three 
correct answers. Fry (2011) mentioned that the relationship between speed and comprehension is paramount: read too fast and we may comprehend less; reading more slowly does not necessarily mean we are not grasping the material. Therefore, reading speed level did not determine students' reading comprehensionsincecomprehension was not dependent on students reading speed level. In this case, students' ability in either lower level processing or higher level processing possibly determined their reading comprehension and determined whether they needed to read slowly or fast.

\section{CONCLUSION AND SUGGESTION}

\section{Conclusion}

This research was aimed at investigating the correlation between students' reading speed level and their reading comprehension. Students' reading speed level, in this research, was measured based on Fry (2011) speed level category, and students' reading comprehension was measured by asking students to answer four questions related to the text being read.

Based on the result of hypothesis test, it could be seen that Spearman's rho value $.608>\alpha=.05$ which meant that alternative hypothesis was not accepted. Thus, there was no significant correlation between students' reading speed level and their reading comprehension.

\section{Suggestion}

There are so many shortcomings and limitations in this research. Therefore, it is imperative have another research on the same topic but in more mature concept of students' reading speed level and their reading comprehension. Theories in reading speed, also known as rate of reading, are mushrooming. Thus, selecting appropriate theories on reading speed or reading rate is certainly crucial to measure students' reading speed level accurately. Providing more aspects in reading comprehension also will accurately measure students' reading comprehension. In addition, providing familiar topic of the text will ease students to get the gist fast.

\section{REFERENCES}

Alderson, J. C., Haapakangas, E.-L., Huhta, A., Nieminen, L., \& Ullakanoja, R. (2015). The Diagnosis of Reading in a Second or Foreign Language. New York: Routledge.

Breznits, Z. (2008). Fluency in Reading: Synchronizatino of Processes. Mahwah: LAC Inc. Publisher.

Brown, H. D. (2000). Teaching by Principles: An Integrative Approach to Language Pedagogy (2 ${ }^{\text {nd }}$ Edition). New York: Routledge

Brown, H. D. (2004). Language Assessment: Principles and Classroom Practices. New York: Pearson Education Inc.

Chen, Xi., Dronjic, V., \& Park, R. H. (2016). Reading in a Second Language: Cognitive and Psycholinguistics Issues. New York: Routledge.

Dorn, L. J., \& Soffos, C. (2005). Teaching for Deep Comprehension: A Reading Workshop Approach. Portland: Stenhouse Publishers.

Fry, R. (2011). Improve Your Reading (6th Edition). Boston: Cengage Leaning PTR.

Grabe, W. (2009). Reading in a Second Language: Moving from Theory to Practice. New York: Cambridge University Press.

Klinger, J. K., Vaughn, S., \& Boardman, A. (2007). Teaching Reading Comprehension to Students with Learning Difficulties. New York: The Guilford Press. 
Paris, S. G., \& Stahl, S. A. (2005). Children's Reading Comprehension and Assessment. Mahwah: LEA Publisher.

Roberts, G. R. (1999). Learning to Teach Reading. London: Paul Chapman Publishing Ltd.

Sadoski,M.(2004).ConceptualFoundations of Teaching Reading. New York: The Guilford Press.

Westwood, P. (2001). Reading and Learning Difficulties: Approaches to Teaching and Assessment. Camberwell: ACERS Ltd.
Wijaya, M. S. (2016). The Correlation Between Prior Knowledge and Skimming Ability in Reading Comprehension of Second Semester Students of English Language Teaching Department at STAIN Jurai Siwo Metro. Pedagogy, 74-81.

Wijaya, M. S. (2016). Pre Reading Acitvities for Muslim and Non Muslim Students. English Education: Jurnal Tadris Bahasa Inggris, 119-131. 